\title{
JUAN ALFONSO DE BAENA Y LOS POETAS DE LA CORTE DE JUAN II EN LAS NOVELAS POPULARES DE M. FERNÁNDEZ Y GONZÁLEZ ${ }^{1}$
}

\author{
María Teresa del Préstamo Landín \\ Universidad de Vigo
}

\section{RESUMEN}

A comienzos de la década de los 50, Manuel Fernández y González publica El condestable Don Álvaro de Luna (1851) y Don Juan el Segundo o el bufón del rey (1853). En ambas historias recrea la corte literaria de Juan II, en la que se entremezclan Juan Alfonso de Baena, Juan de Mena, Jorge Manrique y Rodrigo Cota, cuya presencia resulta determinante para las diferentes intrigas que se gestan contra Luna. En el presente artículo abordaré la función que los poetas representados adquieren en ambas novelas.

Palabras Clave: Manuel Fernández y González, Juan Alfonso de Baena, corte literaria de Juan II, siglo XIX, novela histórica.

\section{Abstract}

At the beginning of the decade of the 50, Manuel Fernandez and González publishes El condestable Don Alvaro de Luna (1851) and Don Juan el Segundo o el bufón del rey (1853). In both histories recreates the literary court of Juan II, in which Juan Alfonso de Baena, Juan de Mena, Jorge Manrique and Rodrigo Cota intermingle and whose presence is determined for the different intrigues that are generated against Luna. In the present article I will address the role that the represented poets acquire in both novels.

KEY WORDS: Manuel Fernández y González, Juan Alfonso de Baena, literary court of Juan II, ninetenth-century, historic novel.

Las novelas El condestable don Álvaro de Luna (1851) y Don Juan el Segundo o El bufón del rey $(1853)^{2}$ suponen casi el inicio de la producción narrativa de Manuel

Recibido: 01-07-2017 / Aceptado: 17-07-2017

${ }^{1}$ Este trabajo se inserta en el ámbito del proyecto FFI 2015-64107-P (MINECO/FEDER, UE).

${ }^{2}$ Cito ambas obras por las ediciones correspondientes a 1851 y 1853, actualizando la ortografía de las citas, a excepción de la incluida en la nota a pie de página número 40 y las sucesivas referencias a la misma, cuya forma respeto. 
Fernández y González (1822-1888). El escritor sevillano, recién llegado a Madrid y a punto de regresar a las filas militares ${ }^{3}$, encuentra en la publicación de El condestable la oportunidad de continuar con su carrera literaria. Esta obra, si bien no supone su primer intento de ficción histórica ${ }^{4}$, es la que le abre las puertas de la capital y de su industria editorial. Un año después, la publicación de Men Rodríguez de Sanabria afianza su nombre y supone el éxito por excelencia de su carrera.

En 1853 Manuel Fernández y González es ya un entreguista profesional y esta fama se ve reflejada en la longitud de la obra y la calidad de los fascículos. Mientras que Don Álvaro de Luna se publica a doble columna — con el consiguiente ahorro de papel que supone-, con grabados y ocupando apenas ocho entregas, Don Juan el Segundo lo hace con un mayor espaciado, con grabados y láminas $\mathrm{y}$, a pesar de la planificación inicial de treinta y seis entregas ${ }^{5}$, llega a alcanzar las ochenta.

Como novelas históricas, aparte de su carácter lúdico tienen la función didáctica de ayudar a entender y difundir el origen de una nación, de un pasado explicado desde la perspectiva del autor decimonónico y desde sus conocimientos e ignorancias, lo que le hará caer inevitablemente en anacronismos. Recurrir a figuras conocidas por el público objetivo facilita en gran medida la labor del novelista. El escritor parte ya de un mundo creado y amueblado por las lecturas previas, un universo habitado por personajes y hechos que son ya $\operatorname{conocidos}^{6}$, así que renuncia al rigor histórico en favor de esta familiaridad ${ }^{7}$, mezclando personajes y hechos de diferentes épocas y que solo

\footnotetext{
${ }^{3}$ F. Hernández-Girbal, Una vida pintoresca: Don Manuel Fernández y González, Madrid, Biblioteca Atlántico, 1931, p. 103.

${ }^{4}$ Previamente a estas dos obras publica las novelas históricas El doncel de don Pedro de Castilla (1838) y las correspondientes a su ciclo morisco, compuesto por La mancha de sangre (1845), Las siete noches de la Alhambra (1848), Allah-Akbar. Leyenda del sitio y conquista de Granada (1849) y El laurel de los siete siglos (1851), que seguirán reeditándose a lo largo de su vida en su versión íntegra o fragmentada.
}

${ }^{5}$ «Constando de treinta y seis entregas próximamente. Una lámina cada entrega, y cada dos se dará otra lámina intercalada en el texto, y otra tirada a dos tintas con una preciosa orla (gratis); a la conclusión se dará el retrato de don Juan II, litografiado a dos tintas y de cuerpo entero» (Anónimo, «Avisos», Diario de Palma, 11 de septiembre [1853], p. 4).

${ }^{6}$ La Castilla de Juan II y don Álvaro de Luna goza en la década de los años cincuenta de plena actualidad por las similitudes existentes entre el monarca medieval y la reina Isabel II, que en este momento cuenta con veinte años, y ha sido ampliamente tratada no solo por las novelas históricas-españolas previas a la publicación de El condestable don Álvaro de Luna -entre ellas, por poner un ejemplo, Los bandos de Castilla (1830) de López Soler-, sino también en la prensa decimonónica, en teatro y en poesía. Entre las novelas coetáneas destaca El condestable de Castilla, de Manuel Torrijos (1858), según M. Ribao Pereira, «Intrigas desde el lecho. Perversiones cortesanas en El condestable de Castilla, de M. Torrijos (1858)», en Jorge Avilés Diz (ed.), Perversiones decimonónicas, Valencia, Albatros, en prensa.

${ }^{7}$ Tal y como señala García Herranz, «Recrear el pasado con sus peculiaridades implica necesariamente que el autor lo haga desde el conocimiento y la perspectiva que se tenga de esa época en el momento en que se escribe su novela, lo que se traduce en un anacronismo inevitable, pero necesario, pues es imprescindible una distancia temporal entre el pasado que se quiere novelar y el momento desde el que se novela». Las inexactitudes temporales son, por tanto un rasgo inseparable de la novela histórica, constituyendo uno de los «múltiples elementos que la configuran: un material histórico conocido y 
tienen en común el formar parte del bagaje cultural del lector.

Manuel Fernández y González refleja en las dos novelas seleccionadas una corte literaria que llegará a ser definida como la "primera edad de oro de la literatura castellana ${ }^{8}$, en la que entremezcla personajes ficticios e históricos, sometidos estos últimos a las necesidades narrativas del autor.

En El condestable don Álvaro de Luna, Fernández y González recrea una corte que alberga y favorece la literatura. El propio rey es definido como un gobernante incapaz, pero con una debilidad por las letras en la que se ampara el escritor para afirmar que la pervivencia de los poetas se debe a su figura:

Insuficiente y nulo, don Juan el Segundo, para gobernar con paz o con gloria sus estados, haciendo respetar por sí mismo su estandarte real a las naciones fronterizas; mezquino para premiar los esfuerzos con que los buenos castellanos lidiaban por reconquistar la dignidad y los fueros nacionales, era entendido y liberal lo bastante para premiar y ennoblecer literatos y poetas, que sin él acaso, como otros muchos en los reinados anteriores, hubieran pasado desconocidos, sofocado su genio bajo el cetro de hierro de la Edad Media: Juan de Mena, Jorge Manrique, Rodrigo de Cotta, el marqués de Santillana, Alonso de Baena y otros, que constituyen la brillante pléyade literaria de este reinado, vivían de su liberalidad, que le hacía empeñar las rentas que le quedaban de las escandalosas concesiones que para sí o para los suyos le acarreaba don Álvaro de Luna9.

Esta debilidad por las letras es atribuida a un proceso de degeneración familiar ${ }^{10}$ y resulta determinante para el personaje hasta el extremo de mantenerse totalmente ajeno al gobierno, a la corte y a sus intrigas, depositando todo su poder en la figura de su valido siempre que esto le permita dedicarse por entero a sus aficiones:

Esto era el resultado preciso de la educación afeminada que le dio su madre la reina doña Catalina de Lancaster, y más la degeneración de la raza de Trastámara. [...] Juan el Segundo, no ya rey sino poeta, a quien debía representarse con una pluma y no con una espada (como aparece en el retrato que acompañamos tomado

cronicado, y un autor con la intencionalidad de evocar una época pretérita, que no puede dejar, necesariamente, de practicar el anacronismo» (A. García Herranz, «Sobre la novela histórica y su clasificación», Epos: Revista de Filología, 25 [2009], p. 302).

${ }^{8}$ A. Circout, «Estudios históricos, políticos, literarios sobre los judíos de España por Don José Amador de los Ríos», Eco literario de Europa. Revista universal, tomo II (1851), p. 63.

${ }^{9}$ M. Fernández y González, El condestable don Álvaro de Luna, Madrid: Imprenta y Librería de Gaspar y Roig Editores, 1851, p. 82.

${ }^{10}$ La caracterización literaria de Juan II que realiza Fernández y González en la novela contrasta con la descripción que Monsalvo Antón defiende de «hombre culto e ilustrado [...] según los cánones de la época, es decir, experto en música y poesía, caza, juegos, justas y torneos, fiestas y toda la panoplia de actividades que se ha dado en llamar [...] "la alegría cortesana" (J. Monsalvo Antón, «Poder y cultura en la Castilla de Juan II: ambientes cortesanos, humanismo autóctono y discursos políticos», en L. E. Rodríguez San Pedro Bezeares y J. L. Polo Rodríguez [coords.], Salamanca y su universidad en el Primer Renacimiento: siglo XV, Salamanca, Universidad de Salamanca, 2011, p. 39). 
de un códice de la época) ${ }^{11}$, en Juan el Segundo, decimos, no se encontraba ni el carácter decidido, emprendedor y guerrero necesario a un rey de aquella época, ni aun el talento del gobierno interior de su familia: dominado siempre por don Álvaro de Luna, esclavizado a su voluntad hasta en sus más íntimas afecciones, abandonado de todos, si no era infeliz era porque ni aun tenía carácter para serlo: la historia le culpa injustamente llamándole tirano, cuando era esclavo [...].

Tal era el hombre, que, solo y abandonado en su cámara, leía tranquilamente un borrador de versos de Juan de Mena, mientras a su alrededor, en su mismo alcázar, hervían las intrigas cortesanas, en el reino la guerra civil y en la frontera los ejércitos invasores ${ }^{12}$.

No obstante, la sola afición del rey a la poesía no resulta suficiente para mantener y proteger la actividad literaria del siglo xv. Monsalvo Antón recuerda que es necesaria una corte igualmente interesada en la que «tanto el Cancionero de Baena [...] como el llamado Cancionero de Palacio [...] constituyen expresiones de este proyecto cultural regio» ${ }^{13}$. Lo que ampara Juan II es una literatura cortesana que, «aunque admitiera la tradición clásica y humanista, al incorporarla desprovista de su idioma original, desvirtuaba dicha tradición y robustecía la lengua vernácula» ${ }^{14}$.

Fernández y González se hace eco de ese ambiente y, junto al rey Juan II, presenta a Juan Alfonso de Baena, al Marqués de Santillana, a Jorge Manrique, a Juan de Mena y a Rodrigo Cota ${ }^{15}$. El principal anacronismo que abordaré es, precisamente, la combinación literaria de estas figuras históricas que difícilmente pudieron haber coincidido. El novelista sevillano afirma que, paralelamente al comienzo de la historia, el poeta cordobés trabaja en su Cancionero ${ }^{16}$. La trama novelesca empieza en el año 1451, mientras que la recopilación se lleva a cabo posiblemente en torno a 1425 y 1430, como indica V. Beltrán ${ }^{17}$. Estos poetas muestran edades demasiado dispares como para

\footnotetext{
${ }^{11}$ Dicho retrato, al igual que el del mismo monarca en Don Juan el Segundo, es prácticamente idéntico al cuadro que Rodríguez de Losada (1826-1896) pinta de Juan I de Castilla. La elección de este retrato y no del correspondiente a Juan II puede deberse, posiblemente, al aspecto más delicado que refleja el pintor sevillano.

${ }^{12}$ M. Fernández y González, El condestable don Álvaro de Luna, ob. cit., p. 82.

${ }^{13}$ J. Monsalvo Antón, ob. cit., p. 39.

${ }^{14}$ Ibidem, p. 47.

${ }^{15}$ En ambas novelas, Fernández y González se refiere a Alonso de Baena y a Rodrigo de Cotta. Reproduzco en las citas las versiones usadas por el novelista, aunque utilizo la más habitual (Juan Alfonso de Baena, Rodrigo Cota) en el resto del artículo.

${ }^{16}$ «Pero en el momento en que estos hombres se convertían, sus hijas eran asediadas por la nobleza, sus hijos tenían abierto el camino para las más altas dignidades, así civiles como eclesiásticas, y ya desde los tiempos de Alonso x encontramos judíos prelados, literatos, estadistas y jurisconsultos: el secretario de don Juan el Segundo, Alonso de Baena, que en la época en que empezamos nuestra historia se ocupaba en compilar un cancionero general, era judío converso y éralo asimismo el obispo de Burgos, don Alonso de Cartagena» (M. Fernández y González, El condestable don Álvaro de Luna, ob. cit., p. 7).

${ }^{17}$ V. Beltrán, «La poesía es un arma cargada de futuro: poética y política en el Cancionero de Baena», en J. L. Serrano Reyes y J. Fernández Jiménez (eds.), Juan Alfonso de Baena y su Cancionero. Actas del I Congreso Internacional sobre el Cancionero de Baena, Baena, Ayuntamiento de Baena, 2002, p. 17.
} 
encontrarse todos en su plenitud literaria en la corte. En el caso de Jorge Manrique, es posible que Fernández y González haya intercambiado su nombre por el de su tío Gómez Manrique ${ }^{18}$.

En El condestable don Álvaro de Luna, la aparición inicial de Juan de Mena y Jorge Manrique tiene lugar en el momento de mayor crispación del motín contra Judit, la joven judía que busca derrocar a Luna en venganza por la muerte de su madre y que, tras la muerte del condestable, descubre ser hija de este. Ambos poetas son recibidos con regocijo por los estudiantes ${ }^{19}$ y a pesar de aparecer acompañados de las lanzas reales y de Alfonso de Estúñiga, guarda mayor del rey, actúan como dulcificador de la ira estudiantil, reprendiendo el comportamiento de los jóvenes:

-Habéis alborotado la villa, dijo con severidad Jorge Manrique; habéis insultado a una dama, faltando al respeto a un gran maestre, y sobre todo, dado lugar a que se grite a vuestra sombra de una manera sediciosa [...].

-Pues bien, retiraos de la puerta y dejad que se cierre: entre vosotros hay traidores... No les sirváis de escabel... Confiad en nosotros, hijos míos, y esperad ${ }^{20}$.

Se introduce en estas intervenciones de Manrique y Mena el tema clave: la traición al régimen. Don Pedro Girón, maestre de Calatrava, quien se encuentra franqueando la puerta, es plenamente consciente de que tras este alzamiento estudiantil se encuentra una rebelión contra el condestable y contra el propio rey en la que los estudiantes son poco más que peones ${ }^{21}$.

En el momento en que transcurre la obra, el año 1451, Mena tiene cuarenta $\operatorname{años}^{22}$, mientras que Manrique cuenta solo con once. No obstante, la descripción que

\footnotetext{
18 «[...] en los años que van hacia 1425-1430, en que pudo efectuar su compilación, Juan Rodríguez del Padrón debió haber alcanzado su madurez literaria, el marqués de Santillana estaba en plena producción, y quizá empezaban ya a lucir su ingenio personajes como Gómez Manrique y Juan de Mena: el propio rey don Juan y Álvaro de Luna fueron también poetas, con cierta constancia el privado, y todos ellos hacían un tipo de poesía totalmente distinta, como se encargaría de demostrar el Cancionero de Palacio» (V. Beltrán, ob. cit., p. 17).

19 «Juan de Mena y Jorge Manrique se vieron rodeados, aclamados, honrados por todos aquellos locos y entusiastas jóvenes, y volvió el estruendo, pero estruendo de aclamación y de amistad» (M. Fernández y González, El condestable don Álvaro de Luna, ob. cit., p. 47).

${ }^{20} \mathrm{Idem}$.

${ }^{21}$ «Nuestra buena universidad, dijo el Maestre de manera que pudiera ser oído por los estudiantes más próximos, sostiene vehemente sus fueros; grita por ellos... acaso más allá de los que debiera; pero son buenos y leales vasallos, lo que no impide el que a su sombra los mal contentos griten por el príncipe don Enrique contra el condestable y contra el rey... No era para rechazar estudiantes para lo que había salido de la vaina mi espada, sino para combatir rebeldes. Ahora creo que no necesitáis de mi licencia caballeros, para pasar y ver que ese buen Rodrigo de Cotta, si bien está herido, no se encuentra en peligro de muerte» (Idem)

${ }^{22}$ A pesar de la falta de datos biográficos, Cañas Gálvez anota el año 1411 como el más probable para el nacimiento de Juan de Mena (F. de P. Cañas Gálvez «Juan de Mena, secretario de latín y cronista del rey: un letrado de la Cancillería Real al servicio de Juan in y Enrique IV», en C. Moya García [ed.], Juan de Mena: de letrado a poeta, Woodbridge, Tamesis, 2015, pp. 11-22.).
} 
se muestra de ambos es muy semejante:

Eran aquellos dos semblantes nobles y francos, en los cuales se retrataba claramente el dolor que les causaba el estado del joven: el que estaba de pie, vestido con un sencillo traje talar, era calvo como su compañero, pero de una manera más enérgica; del mismo modo le superaba en edad: brillaba en entre ambos esa mirada fija, profunda y pensadora de los hombres de genio, y era imposible pensar en la doblez ni en las malas pasiones a la vista de sus semblantes.

El uno, de más edad, el que estaba de pie era Juan de Mena, cronista del Rey; vestía un sencillo traje talar y un manto blanco con orla, y no llevaba armas de ninguna especie: el otro, el que estaba sentado era Jorge Manrique, ceñía únicamente una espada de corte, y vestía una túnica talar de paño, bordada de sedas, y guarnecida de pieles en las mangas de galón de oro en la orla ${ }^{23}$.

La combinación de los dos literatos, presentados como de edades similares, es solo uno de los muchos anacronismos que desarrolla Fernández y González en la obra $^{24}$. Resulta llamativo, así mismo, cómo Manrique desaparece progresivamente de la obra frente al papel constante de Mena. El joven poeta aparece al comienzo junto al cordobés y la siguiente mención que se realiza de su figura es en boca de Rodrigo Cota, quien refiere su ausencia en la lectura de poesías que el rey lleva a cabo a final de año debido a «sus dolencias» ${ }^{25}$. No se especifica cuál es la causa real de su desaparición ni tampoco vuelve a nombrársele a lo largo de la obra. Acaso sea este un guiño de Fernández y González a la oposición de don Rodrigo Manrique ${ }^{26}$, del que -al igual que del resto de vicisitudes del reinado de Juan II- da cuenta la prensa coetánea a la novela ${ }^{27}$.

Rodrigo Cota es, posiblemente, el poeta que más protagonismo cobra en El condestable don Álvaro de Luna (1851). Al comienzo de la novela cumple un papel pasivo, la función del estudiante enamorado de Judit, personaje femenino principal de la obra. Aunque no se especifica su edad en ningún momento de la novela, se sugiere una juventud semejante a la de la dama, en torno a los veinte años de edad.

El argumento de la novela se desarrolla a partir del atentado contra su vida que lleva a cabo la hermandad de Cristo de las Tinieblas, que más adelante se descubre

\footnotetext{
${ }^{23}$ M. Fernández y González, El condestable don Álvaro de Luna, ob. cit., p. 48.

${ }^{24}$ Su tío, Gómez Manrique, nace en 1412, por lo que en la ambientación de la obra contaría con treinta y nueve años, edad que casa más adecuadamente con la descripción dada para su sobrino.

${ }^{25}$ M. Fernández y González, El condestable don Álvaro de Luna, ob. cit., p. 94.

${ }^{26}$ «En 1450 el marqués de Villena, el marqués de Santillana, el conde de Haro, el almirante de Castilla y don Rodrigo Manrique, que se titulaba maestre de Santiago, se coligaron en La Coruña contra su rey, acordando acudiese cada cual con la gente que pudiese reunir para salir con su intento por la vía de las armas» (Anónimo, «Sucesos de España en que individuos de la aristocracia guardaron poca fidelidad a los reyes», El Espectador, 15 de enero [1845], p. 3).
}

${ }^{27}$ M. Ribao Pereira, «Prensa, actualidad política y romanticismo español: el caso de J. Morán y la corte de Juan II de Castilla», Amnis, 14 (2015). 
presidida por el futuro rey Enrique IV y Juan Pacheco. Con la muerte del poeta se pretendía provocar un motín estudiantil que pusiese en entredicho no solo la reputación de Judit, sino también que contribuyese a crear una distracción en la ciudad para dejar vía libre a los planes del príncipe contra el condestable.

-Escucha. Si de casualidad de que esta noche el músico ronde los miradores de doña Judit, se le acuchilla.

$-¡$ ¡Ah!

- ¿Empiezas ya a comprender?

-Sí, sí, señor; entiendo... Y una vez acuchillado se hace correr la voz de que doña Judit es una mala judía, ha hecho asesinar a un estudiante: la universidad, que nunca está mejor que cuando arrastra en un motín sus bayetas ${ }^{28} \ldots$

Tal y como puede observarse en el fragmento, la elección de Rodrigo Cota como víctima es una casualidad. Su importancia radica en lo conocido que resulta en la ciudad el hecho de que acuda regularmente a visitar al verdadero objetivo de la trama, así como su pertenencia a un colectivo, el estudiantil, popularmente conocido por su beligerancia ${ }^{29}$.

El poeta comienza la obra encamado por esta puñalada y continuará así durante prácticamente toda la novela. Sin embargo, participa activamente en la conspiración con una composición satírica que, en la reunión anual que celebra el rey, Baena lee en su nombre. Rodrigo Cota no es más que un instrumento al servicio de intereses políticos ajenos - tal y como afirma la propia Judit ${ }^{30}$ - que al final no consigue premio alguno por su comportamiento ${ }^{31}$.

La noticia del ataque al joven estudiante llega durante la primera de las dos reuniones literarias descritas en la obra. Introducida la primera de una manera leve y superficial, se presenta a los poetas a que antes he aludido junto a Íñigo López de Mendoza, marqués de Santillana. Su presencia se limita a dos breves menciones de las que reproduzco la más importante por retratar su filiación política:

La nueva del percance acontecido a Rodrigo de Cotta había llegado hasta ellos, en ocasión en que Juan de Mena leía a Jorge Manrique y al marqués de Santillana los primeros actos de la Celestina, que acababa de escribir, y La Celestina fue olvidada; los dos nobles poetas corrieron al encuentro e su pobre discípulo: el marqués de Santillana, que era enemigo a muerte del condestable, se escurrió porque había llegado al par la nueva del motín y el guarda mayor del rey hizo cabalgar a cien

\footnotetext{
${ }^{28}$ M. Fernández y González, El condestable don Álvaro de Luna, ob. cit., p. 34.

${ }^{29}$ Obsérvese que los periódicos de la época se hacen eco de las revueltas estudiantiles que sacuden Europa en ese tiempo. En Austria, por ejemplo, los estudiantes toman las armas exigiendo la igualdad de derechos entre austriacos y alemanes (Anónimo, «Correo extranjero», Eco del Comercio, 26 de marzo [1848], p. 4).

${ }^{30}$ M. Fernández y González, El condestable don Álvaro de Luna, ob. cit., p. 99.

${ }^{31}$ Ibidem, p. 184.
} 
hombres de armas para dar con ellos resguardo a los dos poetas ${ }^{32}$.

Fernández y González elimina cualquier vinculación existente entre el marqués de Santillana y el histórico motín para derrocar a Luna, como por ejemplo el intento de asesinato que este lleva a cabo junto con los condes de Haro y Benavente ${ }^{33}$, prescindiendo así de la faceta extraliteraria del noble en la obra.

En cuanto a Mena, Fernández y González le atribuye el primer auto de la Tragicomedia de Calisto y Melibea, lo que en sí mismo resulta llamativo puesto que en el siglo xIX su atribución a Cota estaba muy generalizada ${ }^{34}$.

Cuando el motín organizado para evitar que Judit llegue a ser menina de la reina Isabel fracasa y la judía deja de estar en disposición de tentar al rey con su belleza, Juan de Mena la incita, engañado por su dulzura, a intentar de nuevo el acercamiento al monarca:

- ¿Y no creéis, señora, que haya otra alma más triste, más abandonada, más combatida que la del rey? ¿No creéis que exista una alta y noble dama para la cual vuestra amistad sería un bálsamo de consuelo? [...] Su alteza no conoce ni aún vuestro nombre, señora, porque sois como la perla escondida en su celosa concha; pero yo os he admirado y os quiero para que alegréis con vuestros encantos los profundos pesares de esa real enferma... Pronto, acaso, recibiréis con un noble enviado una súplica de su alteza ${ }^{35}$.

El personaje de Juan de Mena cobra importancia en la parte intermedia de la novela. En el capítulo i de la segunda parte, «Los cortesanos de Juan II», la conversación entre el poeta y la reina permite conocer la profundidad de su relación con el condestable, al cual sirve de manera inconsciente ${ }^{36}$. Isabel de Portugal describe al poeta a partir de una dicotomía literario-política:

[...] el poeta que remonta su pensamiento a Dios, que recibe su inspiración en

\footnotetext{
${ }^{32}$ Ibidem, p. 49.

${ }^{33}$ M. A. Ladero Quesada, El marqués de Santillana, 1398-1458: El hombre de Estado, Hondarribia, Nerea, 2001, p. 29.

${ }^{34}$ «La atribución a Mena, a la que no se dio mayor crédito en lo antiguo, [...] no ha tenido prácticamente valedores». La de Cota, por su parte, «[...] no sólo la sostienen críticos como Ticknor, Clemencín, el Marqués de Pidal o Soravilla [...] sino que además el Diálogo [Dialogo entre el amor y el viejo] suele imprimirse al final de las ediciones de La Celestina, como en las de Madrid, León Amrita, 1822 y 1835, o Barcelona, Tomás Gorchs, 1841 y 1842» (M. Á. Pérez Priego, «Mena y Cota: los otros autores de La Celestina», en F. Pedraza Giménez, G. Gómez Rubio y R. González Cañal [coords.], La Celestina, V centenario (1499-1999): Actas del Congreso Internacional, Cuenca, Universidad de Castilla-La Mancha, 2001, p. 161).

${ }^{35}$ M. Fernández y González, El condestable don Álvaro de Luna, ob. cit., p. 50-51.

${ }^{36}$ Uno de estos servicios accidentales se produce al inicio de la obra, cuando Juan de Mena intercede ante Judith para que esta entre a servicio de la reina Isabel (M. Fernández y González, El condestable don Álvaro de Luna, ob. cit., pp. 50-51).
} 
las alturas y desciende a la tierra para dar a los hombres, envuelto en raudales de armonía, el canto sobrehumano que enaltece las hazañas, diviniza los preceptos, embellece el consuelo y envuelve las almas de los que le escuchan en una embriaguez purísima, se apodera de ellas, las hace enardecerse en bravura o deshacerse en lágrimas: entonces sois mi hombre, mi buen poeta, mi amigo, mis ojos os miran con entusiasmo y mis oídos os escuchan con delicia.

-Y, permitidme, señora: ¿cuándo este hombre, que es tan maravillosa, tan endiabladamente feliz oyendo de vuestros labios tan bondadosas, tan mágicas palabras, cuándo este hombre no alcanza gracia delante de vuestra alteza?

-Cuando ese hombre descendiendo de las alturas, donde todo es divino y puro, arrastra sus alas de oro entre el fango, cuando roba a una pobre mujer su esposo, obedeciendo las órdenes de un miserable, engrandecido por la nulidad del rey... ${ }^{37}$

Juan de Mena comienza la novela como protegido de Luna ${ }^{38}$; sin embargo, conforme avanza la acción, y sin llegar a participar en ningún momento en las intrigas contra él, el personaje evoluciona hasta considerarle casi como un traidor. Así, en el capítulo v de la segunda parte de El condestable, titulado «Una conspiración de poetas», se produce el choque entre estos dos bandos de la corte: don Álvaro interrumpe una reunión del rey con sus poetas ${ }^{39}$, a la que solo faltan Manrique y Cota. En ella se produce el primer enfrentamiento público entre el valido y sus enemigos, el golpe inicial de la conspiración que realmente surte efecto.

La escena se inicia con Juan Alfonso de Baena leyendo un madrigal de amor dedicado a Judit. Mientras todos los poetas, incluyendo entre estos al propio monarca, alaban el poema, Luna cuestiona su origen al dudar de la autoría del mismo. Zúñiga compara los encargos de un poema amoroso y una sátira, ocasión que el propio Baena utilizará para poder leer una nueva composición al condestable. Juan Alfonso recita A la cobdicia ${ }^{40}$, una breve sátira de treinta y dos versos de arte mayor. El poema es

\footnotetext{
${ }^{37}$ Ibidem, p. 74.

${ }^{38}$ El poeta «dedicó al favorito de Juan II tres poemas breves de alabanza, fue el autor del proemio del Libro de las claras e virtuosas mugeres, escrito por el condestable, y además a Mena se atribuyen unas Memorias de algunos linajes, también destinadas a don Álvaro» (C. Moya García, «Juan de Mena, Álvaro de Luna y los Mendoza: literatura y estrategias de linaje», en C. Moya García [ed.], Juan de Mena. De letrado a poeta, Woodbridge, Tamesis, 2015, p. 68).

${ }^{39}$ «El Condestable se encaminó en derechura a la cámara del rey y le encontró gratamente distraído oyendo leer versos a su secretario Alonso de Baena. Acompañábanle sentados familiarmente en derredor de su mesa, el joven Alonso de Zúñiga, uno de sus guardas mayores muy dado a la poesía y a las conspiraciones, según las crónicas; Juan de Mena y el judío converso de Alonso de Baena, secretario del rey, que era el que leía» (M. Fernández y González, El condestable don Álvaro de Luna, ob. cit., p. 91).

40 «Cobdicia es pecado de grande maldad, / por él homecillos, traiciones por él: /al home templado le faz ser cruel / é troca en sobervia la santa humildad. / Quien tiene cobdicia non habrá piedad, / nin cosa que ataje su fambre dañina, / compañanle en torno quebranto é ruina; /é amor non conosce, nin siente amistad. / Cobdicia en privados algunos sentí, / que oculta, en doseles josticias sobyuga, / cual torpe en la planta se esconde la oruga /é horada sus fojas, secándola ansí. / Con sangre de tristes engordar la ví; / con galas agenas en todo lo al; / nascida en lo bajo levarse á lo real, / seyendo potente cual fue baladí. / E ví otra cobdicia facer del señor / homilde cabtivo del que siervo fue, / é fizome espanto, por ende, é dubdé / que á tanta grandeza se alzara un traidor. / De reinas miréle mancillar la
} 
atribuido en un primer momento al poeta cordobés; no obstante, tal y como este revela, pertenece, junto con el madrigal, a la pluma de Cota ${ }^{41}$. Baena se muestra como la cabeza visible de la conspiración, quien se enfrenta al condestable en el campo de batalla más delicado: el que ofrece a sus enemigos la despreocupación política de Juan II.

El texto poético al que acabo de referirme aparece reproducido en la novela en un deliberado estilo antiguo ${ }^{42}$ y no se corresponde con composición alguna de ninguno de los dos poetas. El cambio de temporalidad que se aprecia en los diferentes estilos de la composición y del resto de la novela supone una forma de anacronismo verbal más violenta. Fernández Prieto afirma que «los lectores aceptan que los personajes utilicen un lenguaje que sólo se diferencia del suyo en la aparición aislada de arcaísmos o en el uso de determinadas frases que connotan modos y costumbres» ${ }^{43}$. Fernández y González, adaptando su poema a una suerte de pretendido castellano medieval, va más allá de esa concesión que realiza el receptor, forzándolo a alcanzar un mayor grado de compromiso con la obra.

El poema supone un ataque directo y premeditado contra el condestable ${ }^{44}$. Sin más apariciones a lo largo de la obra, Baena demuestra la realidad de la conspiración, que trasciende el mundo de los rumores:

Asimismo, Juan de Mena reparó en que el joven guarda mayor, Alonso de Zúñiga, ostentaba en su semblante esa serenidad mate, por decirlo así, que demuestra que se sabe lo que se hace, y que se tiene valor para aceptar una responsabilidad, sea cual fuere. Tenía profundamente fijos sus ojos en Alonso de Baena y, cuando alguna vez levantaba la vista del manuscrito y la arrojaba sobre el semblante de Zúñiga, se cruzaba entre aquellos dos hombres una mirada, en que la sagaz inteligencia del poeta comprendía que se ponía en ejecución un plan trazado de antemano; en una palabra, que la lectura de aquella poesía a la codicia, delante del rey, era una conspiración [...].

Esto demostraba a Juan de Mena que, cuando sus enemigos se atrevían a atacar al Condestable, dentro de la cámara real, debía existir una conspiración pujante,

honor; / romper con su diestra de regnos el fuero, / é mas que esforzado soterrar mañero / de altivos fidalgos el claro valor. / E non otra cura á cobdicia tal / que quitos, por ende, los pueblos estén, / que herir con la espada, segando á cercen, / cabeza, que osada cabsó tan grande mal. / Ansi á yerro é fuego é non de otro al, / los médicos vemos que cortan gangrena, / Quien fizo el pecado que pague la pena. / Ansi lo decreta judicial eterna» (Ibidem, p. 92).

${ }^{41} \ll[\ldots]$ en esto hay un engaño inocente: no soy quien ha escrito estas dos composiciones.

-¿Y quién ha sido?

-Un mancebo que, como vos decís, tiene a un tiempo alma de paloma para el amor y corazón de hierro, de león, para el peligro [...] Es el estudiante Rodrigo de Cotta» (Ibidem, p. 93).

42 «Hemos escrito en estilo anticuado estas estancias, para dar una débil muestra de la poesía del siglo XV a aquellos de nuestros lectores que no la conozcan» (Ibidem, p. 92).

${ }^{43}$ C. Fernández Prieto, Historia y novela: poética de la novela histórica, Pamplona, EunSA, 2003, pp. 191-192.

44 «[...] por más que Baena había procurado contenerse, un ligero temblor, una vibración seca en el acento del poeta; los esfuerzos en fin de un enemigo que acusaba y que procuraba disimular su enemistad» (M. Fernández y González, El condestable don Álvaro de Luna, ob. cit., p. 92). 
organizada, a pesar de los descalabros de Palenzuela, de Madrigal, del Abrojo y de Toledo ${ }^{45}$.

Álvaro de Luna al oír la sátira finge desconcierto ${ }^{46}$, mientras busca demostrar poder mediante la toma de posición entre los presentes.

[...] mientras, había tomado no un sitial sin respaldo, como los que ocupaban los tres acompañantes el rey, sino un alto sillón blasonado con las armas reales, que colocó a la izquierda del rey, sentándose en su misma línea, quedando entre don Juan el Segundo y Alonso de Baena que ocupaba el costado izquierdo de la mesa. Por un accidente el sillón del rey no estaba colocado en el centro y don Álvaro partió el centro con él: un extraño a la corte que hubiera entrado de repente en la cámara real, al ver dos hombres sentados con una absoluta igualdad, anciano y altivo el uno, débil y veinte años más joven el otro, y entre ambos descubiertos, porque don Juan el Segundo dejaba de ser rey cuando se dedicaba a las musas, y guardaba respecto a estas y a los poetas que las representaban la más exquisita galantería, al verlos bajo aquel aspecto, decimos, hubiera creído que don Álvaro era el rey ${ }^{47}$ y este su favorito altamente honrado o cuando más un príncipe heredero ${ }^{48}$.

La composición, tal y como he afirmado previamente, es una acusación al condestable de avaricia y traición, tal y como puede observarse en el primer y noveno versos, «Cobdicia es pecado de grande maldad» $\mathrm{y}$ «Cobdicia en privados algunos sentí». No obstante, el ataque más violento se produce en las dos últimas estrofas de la composición:

E ví otra cobdicia facer del señor homilde cabtivo del que siervo fue, é fizome espanto, por ende, é dubdé que á tanta grandeza se alzara un traidor. De reinas miréle mancillar la honor; romper con su diestra de regnos el fuero, é mas que esforzado soterrar mañero

\footnotetext{
${ }^{45}$ Ibidem, pp. 92-93.

${ }^{46}$ «El acento con que pronunció el condestable [...] era jovial, chancero, perfectamente sereno [...]. Juan de Mena [...] notó que a los primeros versos de la obra que Alonso de Baena había bautizado con el nombre de sátira, don Álvaro había palidecido profundamente, que había necesitado hacer un terrible esfuerzo sobre sí mismo para escuchar con paciencia y de una manera, al parecer indiferente, aquel audaz insulto que delante del rey se le echaba a la cara» (Ibidem, p. 92).

${ }^{47}$ La identificación de don Álvaro de Luna con el monarca frente a la inferioridad de don Juan II es una idea ampliamente desarrollada en las novelas de Manuel Fernández y González. El autor la refuerza al mostrar la oposición entre las vestimentas de ambos: «este vestía un simple sayo de paño, con pieles un tanto peladas; su collar de San Miguel [...] era una prenda, porque no podía llamarse alhaja, de hoja de plata sobredorada, usada ya y blanquecina, pendiente de un collar cuyos eslabones de oro macizo enriquecidos con gruesos brillantes: estas que parecen minuciosidades, eran sin embargo cosa de gran vuelto cuando se consideraba filosóficamente hasta qué punto había sido llevado un rey, que tan miserablemente ostentaba en todo, hasta en el vestido al lado de un hombre, en el cual la grandeza era un accesorio, ya se tratase de su morada, de su servidumbre o de su atavío» (Idem).
}

${ }^{48}$ Idem. 
de altivos fidalgos el claro valor ${ }^{49}$.

En esta tercera estrofa, Baena acusa a don Álvaro de la traición máxima a su rey, quien no es más que un simple prisionero suyo. El rumor sobre la relación entre el condestable y María de Aragón, primera esposa de Juan II fallecida apenas seis años antes de tiempo de la narración, es también el motivo esgrimido en Don Juan el Segundo ${ }^{50}$ para la caída de Luna ${ }^{51}$. En ambas novelas, son las propias cartas de la reina las que constituyen la prueba definitiva para la sentencia. Este motivo ya habría supuesto en la novela una condena previa, la de su destierro de 1441.

El rey, quien aparentemente se mantiene al margen de las tramas de poder que sacuden el reino, se ve fuertemente afectado por este ataque:

[...] había visto nublarse el semblante del rey singularmente a la ligera intención con que Baena pronunció el verso De reinas mirele mancillar la honor, porque aquel pobre rey niño aún y abyecto, recordaba con dolor los punzantes celos que había desgarrado su alma, cuando sus cortesanos, mirando solo a su ambición, se atrevieron a despedazársela, acusando a la reina doña María de adulterio con el condestable. Aquello había valido a este un destierro, y solo la debilidad del rey, su credulidad, su imbécil buena fe para decirlo de una vez, habían podido hacer que don Álvaro volviese a la corte ${ }^{52}$.

A través de los ojos de Juan de Mena el lector percibe cómo el primer golpe cae sobre don Álvaro. Nada importa la conspiración previa, pues es este y no los anteriores el que le afecta de verdad y el que precipitará su final ${ }^{53}$. Sin embargo, el rey no es el único personaje cuya fe en Luna se ve sacudida por la composición. El propio poeta, protegido de don Álvaro, cree la acusación:

Si al acabar de oír aquella insolente diatriba don Álvaro hubiese arrancado con cólera el manuscrito a Baena; si después hubiera sucedido uno de los escándalos tan frecuentes en la corte por aquel tiempo y el rey se hubiera visto obligado a guardar tres días el lecho por resultados de una fuerte excitación, tal como la firma de un ordenamiento de muerte contra cuatro o seis o cien nobles, Juan de Mena hubiera creído aquel arranque, la consecuencia de la indignación de un

\footnotetext{
${ }^{49}$ Idem.

${ }^{50} \mathrm{Al}$ contrario que en El condestable Don Álvaro de Luna, en Don Juan el Segundo no existe una relación amorosa entre ambos personajes. La reina María de Aragón se muestra obsesionada con él, mientras que Luna se niega a ceder ante sus deseos.

${ }^{51}$ M. Fernández y González, Don Juan el segundo o El bufón del rey, Madrid, J. Ruiz de Morales, 1853, p. 517.

${ }^{52}$ M. Fernández y González, El condestable don Álvaro de Luna, ob. cit., p. 92.

${ }^{53}$ Previamente a esta escena, el lector ha presenciado cómo Judit encuentra junto a los hermanos de Villafranca las cartas de amor entre María de Aragón y Álvaro de Luna: «[...] cartas de amor de la reina doña María al Condestable... Cartas en que la mujer adúltera se burla del esposo engañado, con el vasallo infame y traidor. [...] ¡Pruebas de traición! Aquí se habla de dar un tósigo al rey, de alzarse con el reino...» (M. Fernández y González, El condestable don Álvaro de Luna, ob. cit., p. 70). Estas cartas supondrán la causa final contra el condestable cuando caen en manos de Juan II (Ibidem, p. 165-166).
} 
Juan Alfonso de Baena y los poetas de la corte de Juan II en las novelas populares de M. Fernández...

alma grande, generosa y valiente, que al verse insultada, rompe por todo y se ensangrienta implacable y poderosa.

Pero vio con dolor, porque amaba a don Álvaro, que hubiera tragado sin alterarse aquella amarga pócima; que había disimulado y esto para Juan de Mena representaba miedo o a lo menos duda ${ }^{54}$.

En la última estrofa del poema de Baena se aboga por la condena a muerte del condestable como única solución viable para los problemas de Castilla, de los que lo responsabiliza:

E non otra cura á cobdicia tal que quitos, por ende, los pueblos estén, que herir con la espada, segando á cercen, cabeza, que osada cabsó tan grande mal. Ansi á yerro é fuego é non de otro al, los médicos vemos que cortan gangrena, Quien fizo el pecado que pague la pena. Ansí lo decreta judicial eterna ${ }^{55}$.

Alonso de Baena, quien se mantiene al margen de la acción durante la novela, se posiciona de esta manera en el bando contrario al maestre. Al comparar ambas composiciones - el madrigal y la sátira- el condestable destaca las diferencias entre $\operatorname{ambas}^{56}$, poniendo en duda la autoría de Baena, quien confiesa que ambas son, en realidad, de Rodrigo Cota. Zúñiga lleva a la reunión sus composiciones, en las que pretende imitar «la melancolía y la dulzura de Manrique y del Marqués de Santillana y en la sátira, usa el lenguaje de los poetas del tiempo del rey don Pedro, y he procurado darle la fuerza del señor Juan de Mena» ${ }^{57}$. Con todos ellos, la conspiración queda al descubierto:

Doña Judit, no satisfecha aun con haber arrancado al condestable de una manera aleve ordenamientos de libertad en cédulas de donación al condestable, se aliaba con una cohorte de poetas, é introducida traidoramente hasta el rey por las musas, le ataca a un tiempo en el corazón y en la cabeza ${ }^{58}$.

En Don Juan el segundo o el bufón del rey (1853) se nombra a los mismos poetas que en la novela anterior, aunque la mayoría no alcanzan a tener presencia física ni protagonismo político en ella. Se mencionan como entretenimiento del rey, siendo su

\footnotetext{
${ }^{54}$ Ibidem, p. 93.

${ }^{55}$ Ibidem, p. 92

${ }^{56}$ «[...] la primera es el alma de un adolescente exhalada en divinas armonías... La segunda... ¡OH! La segunda un noble y valiente grito de indignación en nombre de un rey y de un pueblo. Para poner en práctica el madrigal es necesaria un alma de paloma; para sostener dignamente... la sátira... un corazón de león y un puño de hierro. No os hacía, en verdad, ni lo uno ni lo otro, mi buen Baena... Confieso que no os conocía... Sois un hombre enteramente nuevo para mí» (Ibidem, p. 93).
}

${ }^{57}$ Ibidem, p. 94.

${ }^{58}$ Idem. 
quehacer literario una actividad disuasoria para la toma de decisiones por parte del monarca:

Mejor te fuera seguir teniendo por juguete a tu Juan de Mena, a tu Jorge Manrique, a tu Alonso de Baena y a tu marqués de Santillana: esos, cuando más, solo llegarían a acabarte de secar el seso con sus coplas, estancias y madrigales. Pero tu doña Isabel te secará el corazón, después de haberte reverdecido ${ }^{59}$.

Juan de Mena es el único poeta que adquiere categoría en esta segunda entrega del ciclo de Luna en Fernández y González. Al igual que en El condestable, se describe al poeta como una persona inocente y poco inclinada a las intrigas:

-Señor Juan de Mena - contestó la otra voz ya más serena y sin tartamudear-, vos, como gran poeta que sois, tenéis el corazón de oro puro y no creéis que pueda hacerse otra cosa que lo que se aparente hacer para el bien o para el mal... De modo que estáis expuesto por vuestra buena fe a que un bribón os parezca un hombre honrado, y un hombre de honor un vil, como os acontece ahora con el señor Alonso Pérez de Vivero ${ }^{60}$.

Mena se muestra también en esta novela fielmente partidario del condestable:

-Pero los buenos castellanos, que saben que habéis cargado sobre vuestra cabeza con el peso de la corona de don Juan el II, no os acusan porque gobernéis en su nombre, y de la misma manera no os acusarían aunque obraseis como si realmente fueseis el rey, como si en vez de gritar los sediciosos ;muera el condestable! gritasen imuera el rey! ${ }^{61}$

Y el rey se manifiesta, de igual modo, fuertemente interesado en la literatura, hasta el extremo de acudir los sábados a una «academia de poesía» con los poetas de la corte ${ }^{62}$.

En las dos novelas, Fernández y González refleja una corte en la que los poetas conforman, por su cercanía al rey y por la condición privilegiada de la que disponen, parte de una de las camarillas que rodean al monarca y, a su vez, el arma más efectiva contra el condestable:

-Quiero... Quiero en fin... Ya me conoces: quiero vivir a mi manera.

- ¿Y me daréis mis enemigos?

-¿Quiénes? ¿Mis poetas? ¿Quieres quitarme mi solaz?... No, don Álvaro, pídeme en vez de ellos, por cada uno cien nobles, y te los doy: llévate mi bufón, mi garza y mi mosquete... ¡Pero mis poetas...! Imposible... No consentiré... ni aun en que se les encierre conmigo en el alcázar.

-Ved señor que son traidores

\footnotetext{
${ }^{59}$ M. Fernández y González, Don Juan el segundo o el bufón del rey, ob. cit., p. 251.

${ }^{60}$ Ibidem, p. 366.

${ }^{61}$ Ibidem, p. 367.

${ }^{62}$ Ibidem, p. 592.
} 
-Te tienen alguna ojeriza, maestre: los tratas con poco amor, con poco entusiasmo y ellos son orgullosos... Componte con ellos de otro modo..., dales rentas, Luna..., llévatelos a tu palacio de tiempo en tiempo y halágalos... y ya verás. Te adorarán... como te adora Juan de Mena a quien has sabido honrar. Eso excita su envidia... Hazte de ellos amigos... y de seguro no vendrán con sátiras ni con madrigales de amor.

La voz del rey se hizo sarcástica en estas últimas palabras: don Álvaro no comprendía bien si el rey, a quien un momento antes había creído vencido, lo estaba realmente o se cubría, de miedo, para obrar después libremente ${ }^{63}$.

Fernández y González, quien retrata a Juan in como un personaje aislado de la acción y, por tanto, ignorante de las tramas internas que gobiernan la corte, revela una nueva cara del monarca. El rey es consciente de las conspiraciones que se orquestan contra el condestable y, a pesar de que durante el enfrentamiento que se produce entre los poetas y su valido ninguno mencione el nombre de Luna, ha entendido la acusación que su corte literaria vierte contra él. Esta conversación es la primera prueba que don Álvaro encuentra de su pérdida de poder sobre el reino.

Como suele ser habitual en los títulos históricos ambientados en tiempos de Juan II de Castilla, los lectores decimonónicos reconocen en la corte castellana del siglo XV las intrigas de la suya propia. La reina Isabel II, de apenas veintiún años en el momento en que se publica la primera de las novelas, delega sus obligaciones en las diferentes camarillas que la rodean, grupos de poder que buscan el control del país ${ }^{64}$. Al contrario que Juan II y sus poetas, «Isabel II no tuvo a su alrededor, durante la Década Moderada, un grupo de personajes [...] de cierta altura y capacidad de influencia políticas» ${ }^{65}$, por lo que la reina se encuentra sola y sin apoyos, sin tan siquiera la ayuda que el rey Juan, en su ingenuidad, cree poder encontrar en sus literatos.

\section{BiBLIOGRAFÍA}

Anónimo, «Avisos», Diario de Palma, 11 de septiembre (1853), p. 4. , «Correo extranjero», Eco del Comercio, 26 de marzo (1848), p. 4.

\footnotetext{
${ }_{63}^{63}$ M. Fernández y González, El condestable don Álvaro de Luna, ob. cit., p. 95.

${ }^{64}$ «El otro gran grupo de presión que alentaba en la Corte estaba situado en las antípodas del mundo burgués y moderno que rodeaba a la reina madre. Se trataba del círculo del rey consorte, Francisco de Asís, aquel que con más propiedad y más arcaicos resabios merece el término de camarilla. Su composición era mucho más reducida, más oscura, mucho más reaccionaria y clerical. Entre sus miembros destacaba el padre Fulgencio, confesor particular del rey (...) y la famosa "monja de las llagas", sor Patrocinio. Junto a ellos figuraban otros ilustres reaccionarios como el hermano de sor Patrocinio, el gentilhombre Juan Quiroga, Serafín María de Soto (...) o Trinidad Balboa» (I. Burdiel, Isabel II. Una biografía (18301904), Barcelona, Taurus, 2016, p. 223).

${ }^{65}$ Ibidem, p. 225.
} 
«Sucesos de España en que individuos de la aristocracia guardaron poca fidelidad a los reyes», El Espectador, 15 de enero (1845), p. 3.

BELTRAN, V., «La poesía es un arma cargada de futuro: poética y política en el Cancionero de Baena», en J. L. Serrano Reyes y J. Fernández Jiménez (eds.), Juan Alfonso de Baena y su Cancionero. Actas del I Congreso Internacional sobre el Cancionero de Baena, Baena, Ayuntamiento de Baena, 2002, pp. 15-52.

Burdiel, I., Isabel II. Una biografía (1830-1904), Barcelona, Taurus, 2016.

Cañas GÁlvez, F. DE P., «Juan de Mena, secretario de latín y cronista del rey: un letrado de la Cancillería Real al servicio de Juan II y Enrique IV», en C. Moya García (ed.), Juan de Mena: de letrado a poeta, Woodbridge, Tamesis, 2015, pp. 11-22.

Circout, A., «Estudios históricos, políticos, literarios sobre los judíos de España por Don José Amador de los Ríos», Eco literario de Europa. Revista universal, tomo II (1851), pp. 50-70.

Fernández Prieto, C., Historia y novela: poética de la novela histórica, Pamplona, EunsA, 2003.

FERNÁNDEZ y GONZÁLEZ, M., El condestable don Álvaro de Luna, Madrid, Imprenta y librería de Gaspar y Roig Editores, 1851.

, Don Juan el segundo o El bufón del rey, Madrid, J. Ruiz de Morales, 1853.

García Herranz, A., «Sobre la novela histórica y su clasificación», Epos: revista de Filología, 25 (2009), pp. 301-311.

Hernández-Girbal, F., Una vida pintoresca: Don Manuel Fernández y González, Madrid, Biblioteca Atlántico, 1931.

Ladero Quesada, M. A., El marqués de Santillana, 1398-1458: El hombre de Estado, Hondarribia, Nerea, 2001.

Monsalvo Antón, J., «Poder y cultura en la Castilla de Juan II: ambientes cortesanos, humanismo autóctono y discursos políticos», en L. E. Rodríguez San Pedro Bezeares y J. L. Polo Rodríguez (coords.), Salamanca y su universidad en el Primer Renacimiento: siglo XV, Salamanca, Universidad de Salamanca, 2011, pp. 15 -92.

Moya GarcíA, C., «Juan de Mena, Álvaro de Luna y los Mendoza: literatura y estrategias de linaje», en C. Moya García (ed.), Juan de Mena. De letrado a poeta, Woodbridge, Tamesis, 2015, pp. 55-74.

Pérez Priego, M. Á, «Mena y Cota: los otros autores de La Celestina», en F. Pedraza Giménez, G. Gómez Rubio y R. González Cañal (coords.), La Celestina, V centenario (1499-1999): Actas del Congreso Internacional, Cuenca, Universidad de Castilla-La Mancha, 2001, pp. 147-164.

Ribao Pereira, M., «Prensa, actualidad política y romanticismo español: el caso de J. Morán y la corte de Juan II de Castilla», Amnis, 14 (2015). URL http://amnis. revues.org/2541 [última consulta: 4 de junio de 2017]. 